\title{
E A EDUCAÇÃO FÍSICA? NARRATIVAS DE PROFESSORES-PESQUISADORES SOBRE AS AULAS REMOTAS EM INSTITUTOS FEDERAIS
}

WHAT ABOUT PHYSICAL EDUCATION? NARRATIVES OF TEACHERSRESEARCHERS ABOUT REMOTE LESSONS AT FEDERAL INSTITUTES C

¿Y LA EDUCACIÓN FÍSICA? NARRATIVAS DE PROFESORESINVESTIGADORES SOBRE CLASES REMOTAS EN INSTITUTOS FEDERALES C

doi' https://doi.org/10.22456/1982-8918.117478

Heidi Jancer Ferreira* <heidi.ferreira@ifsuldeminas.edu.br>

Keila Miotto**<keila.miotto@ifsuldeminas.edu.br>

Juscélia Cristina Pereira*** <juscelia@iftm.edu.br>

Josué Lopes*<josue.lopes@ifsuldeminas.edu.br>

Karla Queiroz Gontijo**** <karlagontijo@iftm.edu.br>

Claudia Catarino Pereira***** <claudia.catarino@ifsuldeminas.edu.br>

Renata Beatriz Klehm** <renata.klehm@ifsuldeminas.edu.br>

Wagner Edson F. Santos****** <wagner.santos@ifsuldeminas.edu.br>

\footnotetext{
*Instituto Federal de Educação, Ciência e Tecnologia do Sul de Minas Gerais. Poços de Caldas, MG, Brasil.

**Instituto Federal de Educação, Ciência e Tecnologia do Sul de Minas Gerais. Inconfidentes, MG, Brasil.

***Instituto Federal de Educação, Ciência e Tecnologia do Triângulo Mineiro.

Paracatu, MG, Brasil.

****Instituto Federal de Educação, Ciência e Tecnologia do Triângulo Mineiro. Patos de Minas, MG, Brasil.

*****Instituto Federal de Educação, Ciência e Tecnologia do Sul de Minas Gerais. Pouso Alegre, MG, Brasil.

******Instituto Federal de Educação, Ciência e Tecnologia do Sul de Minas Gerais. Passos, MG, Brasil.
}

Recebido em: 06 ago. 2021 Aprovado em: 20 out. 2021 Publicado em: 26 dez. 2021

Resumo: A implementação do ensino remoto em decorrência da pandemia da covid-19 se configurou como uma nova e complexa realidade para as comunidades escolares. Neste contexto, o objetivo deste trabalho foi analisar as experiências de

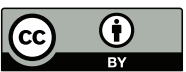

Este é um artigo publicado sob a licença Creative Commons Atribuição 4.0 Internacional (CC BY 4.0). eISSN: $1982-8918$ 
professores-pesquisadores de Educação Física com o ensino remoto em Institutos Federais. Embasada na perspectiva freireana e na teoria social da aprendizagem, a pesquisa foi desenvolvida com abordagem qualitativa e colaborativa através do método da narrativa autobiográfica. Oito professores-pesquisadores participaram do estudo. Os dados foram gerados a partir de narrativas produzidas pelos professores-pesquisadores e foram analisados através de comparações constantes. Como resultados, quatro temas foram identificados: novos cenários e desafios; aproximação e colaboração entre pares; conectando com os estudantes; e repensando as aulas de Educação Física. Em conclusão, as experiências docentes envolveram respostas transformadoras frente aos limites encontrados no ensino remoto, incluindo a escuta dos estudantes e a formação de um grupo de estudos e aprendizagem colaborativa.

Palavras chave: Ensino Fundamental e Médio. Aprendizagem. Pandemias. Covid-19 


\section{INTRODUÇÃO}

O ano de 2020 ficou mundialmente marcado pelo cenário da pandemia da covid-19. A crise sanitária impactou diversos segmentos da sociedade, incluindo as instituições de ensino. Como medida preventiva, escolas foram fechadas em respeito ao distanciamento social, o que demandou a criação de estratégias para possibilitar a continuidade do ensino de forma remota (HOWLEY, 2021; MACHADO et al., 2020).

Com a transição do ensino presencial para o remoto, a disciplina de Educação Física (EF) sofreu uma grande transformação didático-pedagógica, principalmente pelo estabelecimento do processo de ensino-aprendizagem via plataformas virtuais (VILCHEZ et al., 2021; GODOI; KAWASHIMA; GOMES, 2020; VAREA; GONZÁLEZCALVO, 2020). Estudos recentes sobre a realidade da EF no ensino remoto demonstram uma falta de capacitação profissional e dificuldades dos professores com o uso de ferramentas tecnológicas, sentimento de insegurança e ansiedade (GODOI; KAWASHIMA; GOMES, 2020; MACHADO et al., 2020), como também a diversificação e a inovação das vivências nas aulas remotas de EF (VILCHEZ et al., 2021; HOWLEY, 2021; MERCIER et al., 2021).

Howley (2021) aponta que o ensino remoto em EF assumiu diferentes formas de acordo com a variedade de contextos em que foi implementado. Assim, é relevante conhecer as diversas realidades e experiências desenvolvidas em contextos ainda pouco investigados, como os Institutos Federais (IFs) da Rede Federal de Educação Profissional, Científica e Tecnológica.

Considerando que ainda há muito que se entender sobre processos de ensinoaprendizagem em EF de forma on-line ou híbrida, é importante refletirmos sobre as experiências docentes para compreendermos como este período turbulento impactou as aulas de EF e as possíveis implicações futuras para a disciplina (HOWLEY, 2021).

Neste sentido, o objetivo deste estudo foi analisar as experiências de professores-pesquisadores de EF com o ensino remoto em dois IFs durante a pandemia de covid-19. Duas questões nortearam a pesquisa: quais foram os impactos da pandemia nas aulas de EF? Como os professores deste componente curricular têm lidado com as novas realidades de ensino impostas pela pandemia?

\section{BASES TEÓRICAS}

Buscando desvendar as experiências dos professores com a realidade concreta e complexa da EF neste cenário pandêmico, este estudo foi fundamentado pela perspectiva crítica de Freire (2018), noção de experiência (MIRAGEM; ALMEIDA, 2021) e teoria social da aprendizagem (TSA) (WENGER, 2013).

Segundo Freire (2018), vivemos em uma relação dialética no mundo, onde encontramos diversas "situações-limite" como fruto das dimensões concretas e históricas da realidade em que vivemos. Estas "situações-limite" podem ser geradoras de desalento, mas se compreendidas - a partir de uma percepção crítica - como um fato de um determinado momento histórico, é possível estabelecer meios para superá-las. 
Não são as 'situações-limite', em si mesmas, geradoras de um clima de desesperança, mas a percepção que os homens tenham delas num dado momento histórico, como um freio a eles, como algo que eles não podem ultrapassar. No momento em que a percepção crítica se instaura, na ação mesma, se desenvolve um clima de esperança e confiança que leva os homens a se empenharem na superação das 'situações-limite' (FREIRE, 2018, p.126).

"Situações-limite" requerem respostas transformadoras e ensejam a ação sobre a realidade concreta. Considerando a pandemia de covid-19, as respostas transformadoras se fizeram urgentes para manutenção do ensino e garantia do direito à educação. Estas respostas só foram possíveis de serem materializadas pelo protagonismo dos sujeitos envolvidos, evidenciando a noção de experiência como categoria que possibilita a compreensão e a valorização da dimensão do vivido em sua imprevisibilidade e historicidade (MIRAGEM; ALMEIDA, 2021). A experiência envolve reflexão sobre a realidade e nos expõe a incertezas e ao confronto do novo com o antigo, permitindo repensar os limites e possibilidades de ação no contexto educacional (MIRAGEM; ALMEIDA, 2021).

As respostas construídas pelos sujeitos enquanto saberes da experiência incluíram o desenvolvimento profissional dos docentes para enfrentamento desta "situação-limite". Segundo Wenger (2013), a aprendizagem é parte integral da prática social e se dá no contexto das experiências vividas enquanto fenômeno social. $O$ sujeito, a atividade e o mundo se constituem mutuamente e a educação precisa incorporar essa relação mútua.

A TSA pressupõe uma compreensão do sujeito aprendente como um todo, considerando o aspecto motivacional do desenvolvimento de sua identidade num processo constante de tornar-se e o aspecto cognitivo do desenvolvimento do conhecimento no e com o mundo, em contraposição à ideia de transmissão de um corpo de conhecimento sobre o mundo (WENGER, 2013).

Dentre as premissas básicas do processo de aprendizagem descritas por Wenger (2013), destacam-se: "somos seres sociais" e estamos inseridos em comunidades; conhecer requer participação ativa e envolvimento com o mundo; e a aprendizagem deve ser significativa.

\begin{abstract}
A participação, aqui, refere-se não apenas a situações locais de envolvimento em certas atividades e com certas pessoas, mas a um processo mais abrangente de ser participante ativo das práticas de comunidades sociais e construir identidades em relação a essas comunidades [...]. Esta participação molda não apenas o que fazemos, mas também quem somos e como interpretamos o que fazemos (WENGER, 2013, p.248).
\end{abstract}

Assim, a TSA, as noções de "situações-limite" e experiência se apresentam como chaves interpretativas para compreendermos como professores-pesquisadores têm lidado com a realidade de aulas remotas no contexto pandêmico.

\title{
3 DECISÕES METODOLÓGICAS
}

Com uma abordagem qualitativa e colaborativa (GUBA; LINCOLN, 1989), esta pesquisa utilizou o método da narrativa de caráter autobiográfico (JOSSO, 
2020; WITTIZORECKI et al., 2006). Este estudo também se orientou pela noção de professor-pesquisador (STENHOUSE, 1983), reconhecendo a postura investigativa e participação ativa do professor na produção do conhecimento como forma de aproximar a pesquisa aplicada com a prática educacional. Assim, os pesquisadores do estudo, dois professores e seis professoras de EF, foram considerados como professores-pesquisadores (STENHOUSE, 1983).

A coleta de dados abrangeu a produção de narrativas autobiográficas dos professores-pesquisadores entre outubro e novembro de 2020, refletindo as experiências pedagógicas desenvolvidas de março a setembro de $2020^{1}$. Para Wittizorecki et al. (2006), o exercício narrativo exige um esforço da escrita de si que contribui tanto para o processo de pesquisa como para a formação permanente de professores-pesquisadores.

A análise dos dados foi realizada em três níveis: individual, por pares e em grupo (GUBA; LINCOLN, 1989). No processo de análise por pares cada narrativa foi examinada por dois professores-pesquisadores (excluindo-se o autor da narrativa), que procederam primeiramente a uma análise individualizada dos dados e em seguida realizaram uma discussão das análises. Após esta etapa, foi realizada uma análise em grupo com a sistematização dos dados, identificação de temas e elaboração de um quadro síntese de análise.

O processo analítico foi orientado pelo método da comparação constante, possibilitando a análise das aproximações e distanciamentos entre as narrativas dos professores-pesquisadores (CHARMAZ, 2009). Os procedimentos adotados incluíram leituras sucessivas para familiarização com os dados, codificação inicial com a elaboração de temas provisórios a partir de segmentos de dados e codificação focalizada com o desenvolvimento e seleção dos temas relevantes para o objetivo do estudo.

\subsection{CONTEXTO E PARTICIPANTES DO ESTUDO}

Este estudo foi realizado em cinco campi de dois IFs do estado de Minas Gerais em que a EF era componente curricular em cursos técnicos integrados ao ensino médio, portanto, a disciplina era lecionada para estudantes com idades entre 15 e 20 anos. No período do estudo, as aulas de EF em cada campus atenderam em média 417 estudantes de dez turmas, dentre os três anos do ensino médio.

Os dois IFs implementaram o ensino remoto em 17 de março de 2020 (IF1) e 30 março de 2020 (IF2), quase que imediatamente à suspensão das aulas presenciais em 16 e 18 de março de 2020, respectivamente. Nos dois IFs, houve uma padronização quanto às plataformas utilizadas para o ensino remoto, sendo o Google Classroom e Meet, com auxílio de ferramentas adicionais de interação como o e-mail institucional e o aplicativo WhatsApp. A organização das aulas de EF ocorreu de maneira diversa entre os campi, de acordo com as decisões institucionais: (a) em quatro campi as aulas foram realizadas quinzenalmente, e um campus manteve periodicidade semanal; (b) em quatro campi era obrigatória a realização de aulas

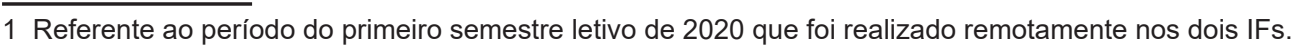


síncronas (embora os estudantes não fossem obrigados a participar simultaneamente e pudessem acompanhar as gravações das aulas disponibilizadas posteriormente), e em um campus cabia ao professor decidir sobre o formato das aulas; (c) a duração das aulas síncronas variou entre 30 e 100 minutos, e a carga horária foi complementada por meio de atividades assíncronas; (d) em todos os campi, foram realizados atendimentos aos estudantes para esclarecimento de dúvidas e interações por mensagens via Google Classroom e e-mail, e em dois campi os professores disponibilizavam pelo menos um horário fixo de atendimento síncrono.

Diante da implementação do ensino remoto, os professores-pesquisadores se uniram em um grupo cujo objetivo foi construir um espaço para troca de experiências e desenvolver estudos sobre as aulas remotas. As reuniões ocorreram quinzenalmente e em formato on-line de maio a dezembro de 2020, totalizando 13 encontros.

A seguir são apresentados brevemente os professores-pesquisadores:

Professora 1: 39 anos, graduada em licenciatura e bacharelado em EF e mestrado em Educação. A construção da identidade como docente e pesquisadora se deu a partir das múltiplas experiências vivenciadas ao longo da atuação nas diversas escolas em que lecionei e no convívio com alunos e colegas de profissão pertencentes a realidades distintas.

Professora 2: 44 anos, 17 anos de experiência, sendo que nos últimos cinco anos tenho atuado com o ensino médio integrado. Concluí o curso de licenciatura plena em EF, assim como minha pós-graduação em nível de especialização e mestrado. Na prática docente busco desenvolver ações que provoquem aproximações entre a EF Escolar e o Desenvolvimento Humano.

Professora 3: 38 anos, atuando há dez anos com o ensino médio integrado. Licenciada e bacharel em EF, mestrado e doutorado em Educação em andamento, me envolvendo com pesquisas na pós-graduação. Busco em minha prática pedagógica apresentar aos alunos a experiência e o conhecimento como possibilidades de transformação.

Professora 4: 33 anos, oito anos de experiência com o ensino médio integrado. Concluí a licenciatura, bacharelado, mestrado e doutorado em EF. O envolvimento com a pesquisa se iniciou na graduação. Na prática pedagógica, busco explorar possibilidades de transformações na vida dos estudantes e sociedade.

Professora 5: 34 anos, atuo há oito anos com o ensino médio integrado. Cursei a licenciatura, bacharelado, mestrado e doutorado em EF. O primeiro contato com a pesquisa ocorreu ainda na graduação. Na docência, busco proporcionar aos alunos um conjunto de saberes e experiências de práticas corporais que podem potencializar e ampliar a sua visão de mundo.

Professor 6: 59 anos, dos quais 31 dedicados ao magistério, ensinando os fundamentos da EF e aprendendo com os alunos. Acertando e errando, mas sempre dando o meu melhor nas condições que me foram ofertadas. A minha formação teve origem na escola pública, fiz licenciatura em EF e mestrado em Educação Tecnológica. 
Professor 7: 50 anos, licenciado e especialista em EF, docente do ensino fundamental, médio, tecnológico e superior há 19 anos, dedicados à formação de discentes em redes públicas de ensino.

Professora 8: 31 anos, licenciatura e mestrado em EF, onde desenvolvi minhas principais pesquisas. Meu fazer docente está diretamente ligado aos conhecimentos estabelecidos a partir da graduação, pós-graduação e atuação como professora na carreira do Ensino Básico, Técnico e Tecnológico.

\section{RESULTADOS E DISCUSSÃO}

Os resultados da pesquisa envolveram quatro temas: (a) novos cenários e desafios, (b) aproximação e colaboração entre pares, (c) conectando com os estudantes, e (d) repensando as aulas.

\subsection{NOVOS CENÁRIOS E DESAFIOS}

Identificamos a existência de três situações vivenciadas pelos professorespesquisadores. A primeira, denominada "mudança drástica", se referiu à transição repentina do ensino presencial para o ensino remoto em um curto período, sem preparação e capacitação dos profissionais. Os impactos foram inevitáveis e surgiram novos desafios.

As aulas presenciais cessaram no dia 16 de março e somente dias após esse fatídico acontecimento, já estávamos retornando as atividades docentes em modo remoto. Uma situação que pegou a todos de surpresa, ninguém estava preparado, sejam docentes, alunos, coordenação pedagógica ou os pais, para uma mudança drástica dessas em tão pouco tempo. (Narrativa 1)

Além do contexto turbulento trazido pela "situação-limite" da pandemia, identificamos a falta de oferta de capacitação para os docentes. Para lidar com as novas necessidades educacionais, os professores precisaram buscar meios próprios de aprendizagem. Estudos anteriores já indicavam que, geralmente, profissionais são introduzidos em ambientes virtuais de aprendizagem sem serem suficientemente capacitados e acabam tendo que mobilizar recursos próprios para desenvolver a docência on-line (MERCIER et al., 2021; LEWIS, 2006).

A segunda situação, denominada "cenário de incertezas", se refere aos momentos em que os professores perceberam que o ensino remoto perduraria por um tempo indeterminado.

Em meio às incertezas, cada instituição escolar buscou diversas alternativas frente a essa situação. Enquanto algumas interromperam totalmente suas aulas, anteciparam as férias escolares, modificaram seus calendários, outras tentaram, através da tecnologia, reinventar suas aulas e continuar remotamente. Essa última foi a decisão adotada pelo Instituto no mês de abril. Desde então, professores tiveram que buscar formas alternativas de ensino. (Narrativa 5)

Houve uma ruptura das rotinas escolares em direção a um futuro desconhecido, em que professores não sabiam como dar continuidade às aulas remotas e precisaram, a partir da experiência, construir respostas para os problemas 
encontrados (MIRAGEM; ALMEIDA, 2021; GODOI; KAWASHIMA; GOMES, 2020; VAREA; GONZÁLEZ-CALVO, 2020).

Já a terceira situação, denominada "desenvolvimento do ensino remoto", caracterizou-se pelo prolongamento da pandemia e do ensino remoto, o que demandou novas formas de enfrentamento para além de uma abordagem de caráter emergencial.

Com o prolongamento da quarentena e o aumento no número de mortes e infectados por covid-19 ficou decidido que as aulas presenciais não retornariam mais em 2020. Assim, decidi por alterar o planejamento inicial, visto que a situação demandava [...]. (Narrativa 1)

Paralelamente, identificamos uma característica comum nos dados coletados: a descaracterização das aulas de EF e ameaça à identidade da área (MACHADO et al., 2020; VAREA; GONZÁLEZ-CALVO, 2020). As narrativas evidenciaram que os professores se depararam com a questão emblemática sobre como ensinar EF em ambiente virtual.

Nem sei quantas vezes eu ouvi: 'como é que se faz para dar aulas de Educação Física à distância?'. Confesso que também não sabia a resposta. Não por falta de conteúdos e/ou possibilidades de desenvolvimento destes, mas eu sabia que do outro lado da tela do computador (ou, na maioria das vezes, da tela do celular) estariam, à minha espera, adolescentes com realidades e condições diversas de enfrentamento da crise causada pela pandemia. (Narrativa 2)

Para os professores, a organização das aulas remotas na ausência da prática, distanciamento dos corpos e artificialização das interações humanas representou um desafio complexo para o qual não tiveram suporte pedagógico adequado.

\footnotetext{
No tocante à Educação Física, a questão do ensino remoto se revelou ainda mais preocupante [...] uma disciplina que se configura em conteúdos da cultura corporal de movimento, que tem como principal característica as aulas práticas, o envolvimento direto nas práticas corporais, o contato, enfim, como se faria o ensino-aprendizado da Educação Física ser significativo e verdadeiro através das telas. (Narrativa 1)

Sem a quadra, sem a prática, sem materiais, sem interações, sem uma pedagogia apropriada [...]. É uma Educação Física de corpos ausentes, invisíveis. Muito tem sido perdido da aprendizagem que ocorre a partir das situações e relações humanas. Mesmo em atividades síncronas, as regras de comportamento em ambiente virtual parecem tornar as interações mais artificiais, o que nos leva a dizer com frequência a expressão 'não é a mesma coisa' (Narrativa 4).
}

Estas situações concretas demonstraram a complexidade das aulas remotas. A especificidade das práticas corporais na EF, a falta de contato com os estudantes e as dúvidas sobre escolhas metodológicas constituíram a experiência das aulas online como um todo complexo.

Alguns desses obstáculos expõem contradições da docência em EF. Para Freire (2018), os obstáculos e "situações-limite" se objetivam historicamente. As questões históricas da EF foram potencializadas no cenário pandêmico: as aulas em ambiente virtual se apresentaram como particularmente desafiadoras considerando que, tradicionalmente, são desenvolvidas a partir do movimento e interações entre 
os estudantes (VILCHEZ et al., 2021; MACHADO et al., 2020; VAREA; GONZÁLEZCALVO, 2020; GODOI; KAWASHIMA; GOMES, 2020).

Ao compreender as "situações-limite" como dimensão concreta e histórica de dada realidade, consideramos que os obstáculos são constituídos historicamente, assim como a superação destes só pode ocorrer também historicamente na experiência (FREIRE, 2018; MIRAGEM; ALMEIDA, 2021). Neste estudo, a constituição dos obstáculos e respostas transformadoras pode ser observada nas novas formas de ensinar EF, incluindo o uso de tecnologias digitais.

\begin{abstract}
No início, enfrentei junto com os alunos o desafio de aprender a utilizar novas ferramentas tecnológicas [...] tivemos que reinventar as nossas práticas de ensino e percebemos que existem possibilidades de trabalho e ferramentas tecnológicas disponíveis que contribuem para os processos educativos. (Narrativa 4)

Muitos já tinham familiaridade com ferramentas digitais, enquanto alguns tiveram que aprender sobre os recursos de ensino. Eu me insiro nessa última situação, pois desconhecia plataformas virtuais de cunho educacional. Além da exigência de ter que aprender de forma repentina o uso de tais ferramentas. (Narrativa 5)
\end{abstract}

Algumas fragilidades da formação docente ficaram notórias. Os professores em geral não estavam preparados para a docência via tecnologias digitais. Assim, a superação de parte dos desafios do ensino remoto partiu da formação continuada dos professores, contribuindo para qualificar os processos de ensino-aprendizagem no contexto pandêmico.

\title{
4.2 APROXIMAÇÃO E COLABORAÇÃO ENTRE PARES
}

A "situação-limite" da pandemia não somente trouxe novos desafios como também evidenciou problemas já existentes no contexto escolar, como a falta de suporte técnico e pedagógico para a docência. $\mathrm{Na}$ insuficiência de apoio para a transição para o ensino remoto, os professores-pesquisadores mobilizaram os recursos disponíveis e se engajaram em processos formativos, por meio dos quais puderam desenvolver a própria aprendizagem a partir da experiência (WENGER, 2013).

Na narrativa 1, a aprendizagem dos docentes pode ser considerada como um avanço: "Como pontos positivos desse cenário, posso dizer que os professores demonstraram sua capacidade de adaptação e de aprendizado, visto que a grande maioria desconhecia as ferramentas didáticas virtuais". Essa perspectiva também foi relatada na narrativa 4: "o ensino remoto nos trouxe oportunidades de novas aprendizagens, tanto para alunos como para professores".

Os limites e possibilidades da realidade concreta proporcionaram uma aproximação entre pares e se configurou como uma estratégia importante para o desenvolvimento profissional de professores. Assim, os professores-pesquisadores formaram um grupo com o intuito de compartilhar experiências e discutir a prática pedagógica no ensino remoto. 
experiências entre professores, de escuta das dúvidas, das incertezas, dos sucessos e fracassos e, na medida do possível, discussões de estratégias para a disciplina de Educação Física no ensino remoto. (Narrativa 5)

Enquanto um processo de construção, essa experiência foi permeada por desafios e entraves. O primeiro foi discutir como operacionalizar o grupo e analisar se iria funcionar. Para que a experiência fosse significativa, a participação no grupo deveria ser de forma voluntária, criando um espaço de suporte ao pensamento coletivo e que fosse de interesse comum a todos. (Narrativa 8)

A experiência de formação do grupo de professores-pesquisadores consistiu em aprendizagem como prática social, envolvendo a participação ativa e engajamento mútuo como forma de conhecer (WENGER, 2013). O grupo assumiu um caráter de suporte pedagógico, mas também de apoio emocional em relação ao sentimento de abandono dos professores-pesquisadores:

O grupo se sentia à deriva diante das dificuldades que se apresentavam, inseguro na tomada de decisões em relação à prática pedagógica de conteúdos historicamente desenvolvidos de forma prática e que passaram, repentinamente, a serem ministrados em ambientes virtuais de aprendizagem. A transição das aulas presenciais para aulas remotas, algo até então impensado para a Educação Física, gerou angústias que somente foram amenizadas com as conversas do grupo e o desenrolar das reuniões. (Narrativa 8)

A aproximação e a colaboração entre os professores-pesquisadores durante esse período turbulento podem ser consideradas não apenas como um resultado imediato. Cabe destacar que, anteriormente à pandemia, nos dois IFs não havia nenhum tipo de organização coletiva voltada para o diálogo e reflexão sobre a EF Escolar. O cenário pandêmico funcionou como um gatilho para a prática colaborativa docente e impulsionou a formação do grupo. Potencialmente, esse grupo poderá propiciar um contexto para a formação docente continuada (VANGRIEKEN et al., 2017) e possibilitar ações futuras voltadas para o fortalecimento da EF nos IFs.

\subsection{CONECTANDO COM OS ESTUDANTES}

As trocas de experiências realizadas pelo grupo de professores-pesquisadores propiciaram o desenvolvimento de estratégias para lidar com o desafio da conexão ${ }^{2}$ com os estudantes durante as aulas remotas. Os professores perceberam dificuldades de interação com os estudantes em ambiente virtual e, ao longo das aulas, um nível reduzido do envolvimento deles com as atividades remotas (HOWLEY, 2021; LUGUETTI et al., 2021; MACHADO et al., 2020):

Com o passar das semanas, detectei que a participação dos alunos foi diminuindo gradativamente tanto no horário de aula quanto na entrega de atividades. Nesse momento, percebi que precisava 'parar' e 'ouvir' o meu aluno, entender quais eram os seus sentimentos diante de tantas situações novas, como estava sendo sua rotina diariamente e qual era a sua opinião/ sugestão em relação às atividades remotas. (Narrativa 5)

O diálogo desempenha papel essencial no processo de ensino-aprendizagem. A educação ocorre em mediação com o mundo e parte do diálogo (FREIRE, 2018).

\footnotetext{
2 Inicialmente, evidenciaram-se os problemas de acesso dos estudantes à internet e equipamentos para acompanhamento das aulas remotas. Contudo, esses problemas foram amenizados com a implementação de políticas de assistência nas instituições participantes do estudo.
} 
Sem o diálogo, não existe comunicação. Sem comunicação, não existe educação. Sendo assim, encontramos no silêncio uma das principais fragilidades do ensino remoto.

$\mathrm{Na}$ fronteira entre os limites e as possibilidades trazidas com a pandemia (MIRAGEM; ALMEIDA, 2021), os professores-pesquisadores buscaram transformações nas próprias práticas pedagógicas, incluindo a escuta e acolhimento dos estudantes. O diálogo se apresentou como elemento central para a reorientação do processo de ensino-aprendizagem (FREIRE, 2018). De fato, os desafios do mundo em pandemia tornaram urgente o estabelecimento de novas vias de diálogo para a constituição das experiências pedagógicas.

Em resposta, os professores-pesquisadores desenvolveram colaborativamente um instrumento ${ }^{3}$ de avaliação diagnóstica para identificar as diversas realidades em que os estudantes estavam inseridos, bem como para ouvir e acolher os estudantes.

A proposta da avaliação diagnóstica foi positiva, pois proporcionou uma visão ampla das condições de saúde e qualidade de vida em que os nossos estudantes estavam nesse período de isolamento social e trabalho remoto. Ao lado disso, foi também uma ferramenta que me auxiliou no planejamento das atividades remotas. (Narrativa 6)

Os alunos apontaram algumas questões em relação às aulas de Educação Física no ensino remoto: aulas cansativas, excesso de textos para leitura e lista extensa de exercícios. As principais reivindicações dos alunos visavam algo mais prático que eles pudessem fazer em casa e que as explicações do conteúdo fossem complementadas com vídeos e tarefas que eles pudessem interagir com sua turma. Diante disso, percebi a necessidade de reorganizar e ressignificar os conteúdos, bem como aprender novas ferramentas tecnológicas para melhorar a qualidade das aulas e o interesse dos alunos pela disciplina. (Narrativa 5)

A experiência de buscar o diálogo com os estudantes permitiu a identificação de limites e possibilidades para as aulas remotas de EF. Para Freire (2018, p.121), "o momento deste buscar é o que inaugura o diálogo da educação como prática da liberdade. É o momento em que se realiza a investigação do que chamamos de universo temático do povo ou o conjunto de seus temas geradores".

Além do instrumento desenvolvido, a escuta dos estudantes tornou-se uma estratégia presente ao longo da prática de duas professoras:

Entre uma aula e outra, a conversa sobre as suas necessidades, o que gostariam de aprender, de executar, e assim vamos nos organizando no planejamento. Tenho recebido pedidos de atividades práticas, porque se sentem muito parados, o dia todo sentados em frente ao computador estudando [...]. Entre todas as atividades, sempre estávamos em busca de entender quais eram as necessidades de nossos alunos. (Narrativa 3)

Adotei outras estratégias como forma de compreender a perspectiva dos estudantes, como fóruns com questões geradoras sobre as atividades realizadas, relatos de experiências, autoavaliação e oferta de opções para a realização de atividades, em que a escolha de cada estudante

\footnotetext{
3 Neste instrumento foram abordados aspectos sobre saúde física e mental, prática de atividade física, comportamento sedentário, sono, uso do tempo para estudos e lazer, mudanças de rotina e uma avaliação geral sobre as aulas remotas de EF com espaço aberto para críticas, demandas e sugestões.
} 
refletia os gostos, interesses e preferências em relação ao conteúdo em foco. (Narrativa 4)

A inclusão de oportunidades de escolhas para os estudantes ao longo das atividades tem sido considerada como prática importante para aumentar a participação nas aulas de EF (VILCHEZ et al., 2021). As experiências dos professorespesquisadores no ensino remoto mostraram a preocupação com a interação e engajamento dos estudantes nas atividades propostas. Entretanto, apesar do esforço dos professores, a construção dos processos de escuta e aproximação com os estudantes não foi linear e apresentou dificuldades.

De novidade criei um tópico no Google Sala de Aula - 'Fórum' para dúvidas e discussões. A intenção foi melhorar a interação entre aluno e professor. Entretanto, creio que não houve interação significativa, e quase não foi utilizado pelos estudantes para tirar dúvidas. (Narrativa 6)

Portanto, os professores apresentaram preocupações com a falta de contato durante as atividades e narraram experiências de busca pela (re)conexão com os estudantes por meio de estratégias voltadas para o acolhimento. Por sua vez, a escuta dos estudantes suscitou reflexões entre os professores sobre as aulas.

\subsection{REPENSANDO AS AULAS}

Os limites encontrados pelos professores-pesquisadores com o ensino remoto levaram a um processo de reestruturação das aulas e produção de saberes da experiência (MIRAGEM; ALMEIDA, 2021). Esse processo de reorganização pedagógica tem sido apontado como a "reinvenção" das aulas de EF (MACHADO et al., 2020; GODOI; KAWASHIMA; GOMES, 2020). Neste estudo, os professorespesquisadores buscaram reelaborar o planejamento de ensino a partir das perspectivas dos estudantes. Na narrativa 7, o professor priorizou a relevância dos temas diante do contexto pandêmico: "procurei observar quais os conteúdos que poderiam ser mais relevantes nesse momento de pandemia covid-19 para os nossos educandos e que pudessem contribuir ou ao menos amenizar tal momento". Essa preocupação também foi apresentada na narrativa 1 :

\footnotetext{
Seria importante trabalhar conteúdos que trouxessem significância e contribuição para o momento que os alunos estavam vivenciando como: o isolamento em casa, a falta de contato com amigos e familiares, pouca ou nenhuma prática de atividade física, os aspectos psicológicos e fisiológicos afetados pelo isolamento, entre outros.
}

Assim, os professores adotaram como critério para selecionar os conteúdos o potencial de diálogo com a realidade concreta dos estudantes. Segundo Freire (2018), a situação presente, existencial e concreta, acaba por refletir o conjunto de aspirações dos professores e dos estudantes, e é neste lugar da experiência que se torna possível organizar o conteúdo programático. Sobre o planejamento de ensino, na narrativa 3 verificamos que "as escolhas dos conteúdos das aulas acontecem de acordo com as necessidades e realidade dos meus alunos". 
Inicialmente, os professores priorizaram a dimensão conceitual dos conteúdos, corroborando os achados de Machado et al. (2020) entre professores da educação básica do estado do Rio Grande do Sul. Na narrativa 6, o professor evidenciou que "o critério utilizado foi considerar aspectos conceituais e socioculturais". Similarmente, podemos observar na narrativa 4:

Diante da dificuldade de desenvolver componentes práticos e tradicionais da Educação Física, vislumbrei possibilidades para elaborar propostas pedagógicas focadas em discussões teórico-críticas relacionadas às práticas corporais, como, por exemplo, a evolução das mulheres nos esportes [...].

Outro critério também adotado pelos professores para a seleção dos conteúdos foi o potencial para estimular a interação familiar.

Pareceu-me mais coerente estimular os estudantes a conhecer temas e atividades que pudessem, de alguma forma, ajudá-los e/ou provocálos a se relacionar com as pessoas as quais a convivência seria mais intensa do que poderiam imaginar e/ou desejar: sua família (ou a falta dela). (Narrativa 2)

O incentivo à participação e integração familiar nas aulas on-line de EF tem sido apontado como um benefício inesperado durante o período de ensino remoto (VILCHEZ et al., 2021). Outros saberes produzidos a partir da experiência incluíram o uso criativo de ferramentas tecnológicas para modificar as aulas (VILCHEZ et al., 2021; LUGUETTI et al., 2021, GODOI; KAWASHIMA; GOMES, 2020), atenção personalizada aos estudantes e oferta de feedback (VILCHEZ et al., 2021; LUGUETTI et al., 2021), e uma maior flexibilidade com as políticas de ensino e avaliação com o intuito de favorecer a inclusão de estudantes que estavam enfrentando dificuldades para o acompanhamento das aulas remotas (HOWLEY, 2021; VILCHEZ et al., 2021).

De maneira geral, os conteúdos trabalhados durante as aulas remotas de EF tiveram como principal foco o tema articulador da saúde. Na narrativa 7 também ficou evidente que "a principal preocupação foi frisar os conteúdos relacionados à saúde". Na narrativa 4: "a pandemia afetou os corpos, o movimentar-se, as interações sociais e o cotidiano dos alunos. Além disso, a pandemia colocou em evidência o grande tema da saúde". Segundo os estudos de Vilchez et al. (2021) e Machado et al. (2020), professores perceberam as aulas de EF como essenciais no período de pandemia por se tratar de um componente curricular que tematiza conteúdos relacionados à saúde, portanto, poderiam contribuir para os estudantes ampliarem a compreensão sobre a situação vivenciada.

Além dos tópicos relacionados à saúde, os conteúdos das aulas remotas envolveram as unidades temáticas de ginásticas, jogos e brincadeiras, esportes e danças, conforme descrito no Quadro 1. 
Quadro 1 - Descrição resumida dos conteúdos e atividades desenvolvidas pelos professores do estudo nas aulas remotas de EF.

\begin{tabular}{|c|c|c|c|}
\hline Temas & $\begin{array}{c}\text { Número de } \\
\text { professores } \\
\text { que abordaram } \\
\text { o tema }\end{array}$ & Tópicos abordados & $\begin{array}{c}\text { Exemplos de estratégias } \\
\text { metodológicas e atividades } \\
\text { desenvolvidas }\end{array}$ \\
\hline Saúde & 7 & $\begin{array}{l}\text { Benefícios da atividade física } \\
\text { para a saúde, envelhecimento } \\
\text { e capacidade funcional, hábitos } \\
\text { alimentares, qualidade de vida, } \\
\text { saúde mental, autocuidado, } \\
\text { autoconhecimento, educação } \\
\text { postural e aptidão física. }\end{array}$ & $\begin{array}{l}\text { Abordagem conceitual, } \\
\text { desafios práticos, projetos } \\
\text { de atividade física, dicas } \\
\text { de saúde com equipe } \\
\text { multiprofissional, histórias de } \\
\text { vida, propostas de prática } \\
\text { de exercícios físicos em } \\
\text { casa, mapa mental, aulas } \\
\text { expositivas, videoaulas e } \\
\text { formulários de questões. }\end{array}$ \\
\hline Ginásticas & 5 & $\begin{array}{l}\text { Histórico, tipos de ginásticas, } \\
\text { movimentos principais, } \\
\text { ginásticas de condicionamento } \\
\text { físico (Pilates, treinamento } \\
\text { funcional, crossfit) e de } \\
\text { conscientização corporal } \\
\text { (yoga, alongamento) }\end{array}$ & $\begin{array}{l}\text { Mapa mental, produção de } \\
\text { vídeos e fotos, vivências, } \\
\text { desafios de exercícios e } \\
\text { relatos de experiências. }\end{array}$ \\
\hline $\begin{array}{c}\text { Jogos e } \\
\text { brincadeiras }\end{array}$ & 5 & $\begin{array}{l}\text { Jogos e brincadeiras } \\
\text { tradicionais e virtuais, } \\
\text { recreação e esportes } \\
\text { eletrônicos, jogos cooperativos } \\
\text { e jogos indígenas. }\end{array}$ & $\begin{array}{c}\text { Entrevistas e realização } \\
\text { de jogos com familiares, } \\
\text { atividades recreativas } \\
\text { elaboradas pelos estudantes, } \\
\text { oficina de brinquedos, } \\
\text { adaptação de esportes } \\
\text { eletrônicos, vivências com } \\
\text { jogos virtuais e produção de } \\
\text { textos. }\end{array}$ \\
\hline $\begin{array}{c}\text { Temas } \\
\text { socioculturais }\end{array}$ & 4 & $\begin{array}{l}\text { Culto ao corpo, doping, } \\
\text { racismo e ética no esporte, } \\
\text { inclusão e EF adaptada, } \\
\text { participação de mulheres nas } \\
\text { práticas corporais. }\end{array}$ & $\begin{array}{l}\text { Análise de documentários, } \\
\text { elaboração de histórias e } \\
\text { formulário de questões. }\end{array}$ \\
\hline Esportes & 3 & $\begin{array}{l}\text { Histórico, esportes olímpicos } \\
\text { e paralímpicos, anatomia } \\
\text { aplicada ao esporte. }\end{array}$ & $\begin{array}{c}\text { Seminários, biografias de } \\
\text { atletas e atividades de } \\
\text { pesquisa. }\end{array}$ \\
\hline Danças & 3 & $\begin{array}{l}\text { Danças folclóricas, danças } \\
\text { urbanas, criatividade e } \\
\text { sincronia na dança. }\end{array}$ & $\begin{array}{l}\text { Vivências, produção de } \\
\text { vídeos, exercícios criativos e } \\
\text { formulário de questões. }\end{array}$ \\
\hline
\end{tabular}

Fonte: Dados da pesquisa.

As narrativas dos professores indicaram que os conteúdos selecionados enfatizaram a importância dos cuidados com a saúde física e mental em tempos de pandemia, bem como conhecimentos sobre o corpo e aspectos socioculturais, como questões raciais e de gênero nos esportes.

Os relatos de dores musculares pela maioria dos alunos direcionaram a inclusão de temas sobre postura corporal, desvios posturais e exercícios de alongamentos, buscando conscientizá-los quanto à importância de adotar uma posição adequada no cotidiano, principalmente durante os momentos de estudos. (Narrativa 5) 
Em relação às formas de desenvolvimento dos conteúdos, os professores diversificaram as estratégias de ensino e avaliação. As estratégias metodológicas representaram uma mudança na prática pedagógica dos professores, uma vez que incluíram o uso de tecnologias.

Em relação às metodologias utilizadas, o foco foi a diversificação de estratégias com o objetivo de manter o envolvimento dos estudantes. Possibilidades adicionais de ensino que antes não eram tão utilizadas em nossas aulas passaram a ser mais exploradas, incluindo o uso de videoaulas, leitura de textos, gravação de áudios, elaboração de mapas mentais, uso de formulários eletrônicos, uso de plataformas virtuais de jogos, e um desafio de exercícios realizados em casa. (Narrativa 4)

O replanejamento de conteúdos e estratégias metodológicas constantemente foram objeto de discussão e motivo de insegurança entre os professorespesquisadores.

O maior desafio ao iniciar o ensino remoto estava pautado no conteúdo, como adaptá-lo ao ensino remoto, instrumento de avaliação, ferramenta a ser utilizada, e o processo de ensino-aprendizagem. A questão principal: os alunos estão aprendendo? (Narrativa 6)

Neste contexto, os professores buscaram diversificar os instrumentos avaliativos, como a elaboração de mapas mentais, infográficos, relatos de experiências, produção de vídeos, fotografias e murais colaborativos, autoavaliação, participação em fóruns de discussão e seminários.

Assim, os professores-pesquisadores reconheceram os desafios partilhados e construíram possibilidades transformadoras para as aulas de EF em ambiente virtual (FREIRE, 2018). A realidade complexa exigiu, no campo da experiência, a construção de soluções também complexas envolvendo a aprendizagem dos sujeitos (professores, estudantes e comunidade escolar) nas relações e práticas de uns com os outros (WENGER, 2013).

\section{CONCLUSÃO}

Este estudo buscou analisar as experiências de professores-pesquisadores de EF com o ensino remoto em dois IFs durante a pandemia de covid-19. Os resultados encontrados indicaram que, diante da "situação-limite" gerada pela pandemia, as experiências dos professores-pesquisadores abrangeram desafios com os novos cenários, bem como o desenvolvimento de práticas transformadoras.

Os professores-pesquisadores enfrentaram desafios relacionados à transição repentina para o ensino remoto, a falta de suporte e capacitação profissional, e a necessidade de aprender a utilizar tecnologias em aula. Por outro lado, os professores também narraram experiências de reflexão sobre as aulas de EF, a incorporação de novas formas de ensino, a implementação de práticas de escuta dos estudantes, e a aproximação e colaboração entre pares.

Diante das dificuldades impostas pela pandemia, os professores precisaram se adaptar ao novo cenário educacional e se engajaram mutuamente com a formação de um grupo enquanto um espaço de aprendizagem profissional. 
Acreditamos que o formato de ensino on-line e híbrido apresentará uma tendência de crescimento em diferentes contextos educacionais no cenário póspandemia. Neste sentido, entendemos que as experiências docentes com o ensino remoto exploradas neste estudo podem ser úteis para reflexões a longo prazo, tais como a problematização do uso de tecnologias na educação, o planejamento em EF, e a necessidade de investimento no desenvolvimento profissional de docentes frente às demandas sociais.

\section{REFERÊNCIAS}

CHARMAZ, Kathy. A construção da teoria fundamentada: guia prático para análise qualitativa. Porto Alegre: Artmed, 2009.

FREIRE, Paulo. Pedagogia do oprimido. 66.ed. Rio de Janeiro: Paz e Terra, 2018.

GODOI, Marcos; KAWASHIMA, Larissa Beraldo; GOMES, Luciane de Almeida. "Temos que nos reinventar": os professores e o ensino da EF durante a pandemia de COVID-19. Dialogia, n. 36, p. 86-101, set./dez. 2020. Disponível em: https://periodicos.uninove.br/ dialogia/article/view/18659/8705. Acesso em: 22 jun. 2021.

GUBA, Ergon G.; LINCOLN, Yvonna S. Fourth Generation Evaluation. Newbury Park: Sage, 1989.

HOWLEY, Donal. Experiences of teaching and learning in K-12 physical education during COVID-19: an international comparative case study. Physical Education and Sport Pedagogy, 2021. Disponível em: https://doi.org/10.1080/17408989.2021.1922658 . Acesso em: 23 jun. 2021.

JOSSO, Marie-Christine. Histórias de vida e formação: suas funcionalidades em pesquisa, formação e práticas sociais. Revista Brasileira de Pesquisa (Auto) Biográfica, v. 5, n. 13, p. 40-54, 2020. DOI: https://doi.org/10.31892/rbpab2525-426X.2020.v5.n13.p40-54

LEWIS, Tim. When teaching is learning: A personal account of learning to teach online. Calico Journal, v. 23, n.3, p. 581-600, 2006. Disponível em: http://www.jstor.org/ stable/24156360 . Acesso em: 22 jun. 2021.

LUGUETTI, Carla et al. The (im)possibilities of praxis in online health and physical education teacher education. European Physical Education Review, p.1-21, jun. 2021. Disponível em: https://doi.org/10.1177/1356336X211016485. Acesso em: 27 Oct. 2021.

MACHADO, Roseli Belmonte et al. EF escolar em tempos de distanciamento social: panorama, desafios e enfrentamentos curriculares. Movimento (Porto Alegre), v. 26, p. e26081, jan./dez. 2020. DOI: https://doi.org/10.22456/1982-8918.106233. Disponível em: https://seer.ufrgs.br/Movimento/article/view/106233. Acesso em: 15 maio 2021.

MERCIER, Kevin et al. Physical education teachers' experiences with remote instruction during the initial phase of the COVID-19 pandemic. Journal of Teaching in Physical Education, v. 40, n. 2, p. 337-342, 2021.

MIRAGEM, Antônio Azambuja; ALMEIDA, Luciano de. Potencialidades e limitações da educação física no ensino remoto: o efeito pandemia no componente curricular. Movimento (Porto Alegre), v. 27, p. e27053, jan./dez. 2021. DOI: https://doi.org/10.22456/19828918.111633 Disponível em: https://seer.ufrgs.br/Movimento/article/view/111633. Acesso em: 04 out. 2021. 
STENHOUSE, Lawrence. The relevance of practice to theory. Theory Into Practice, v. 22, n. 3, p. 211-215, 1983.

VANGRIEKEN, Katrien et al. Teacher communities as a context for professional development: A systematic review. Teaching and Teacher Education, v. 61, p. 47-59, 2017.

VAREA, Valeria; GONZÁLEZ-CALVO, Gustavo. Touchless classes and absent bodies: teaching physical education in times of Covid-19. Sport, Education and Society, 2020. Disponível em: https://www.tandfonline.com/doi/full/10.1080/13573322.2020.1791814 . Acesso em: 23 jun. 2021.

VILCHEZ, Jocelyn A. et al. Teachers and School Health Leaders' Perspectives on Distance Learning Physical Education During the COVID-19 Pandemic. Journal of School Health, v. 91, n. 7, p. 541-549, 2021. Disponível em: https://onlinelibrary.wiley.com/doi/10.1111/ josh.13030. Acesso em: 23 jun. 2021.

WENGER, Etienne. Uma teoria social da aprendizagem. In: ILLERIS, Knud. Teorias contemporâneas da aprendizagem. Porto Alegre: Penso, 2013. p. 246-257.

WITTIZORECKI, Elisandro Schultz et al. Pesquisar exige interrogar-se: A narrativa como estratégia de pesquisa e de formação do(a) pesquisador(a). Movimento (Porto Alegre), v. 12, n. 2, p. 9-33, 2006. DOI: https://doi.org/10.22456/1982-8918.2904 
Abstract: The implementation of remote learning as a result of the COVID-19 pandemic has become a new and complex reality for school communities. In this context, this study analysed the experiences of Physical Education teachersresearcher with remote learning at Federal Institutes. Based on the Freirean perspective and social learning theory, the study was based on a qualitative and collaborative approach, through autobiographical narrative method. Eight teachersresearchers participated in the study. Data were generated from narratives produced by teachers-researchers and were analysed through constant comparisons. Four themes were identified as findings: new scenarios and challenges; peer collaboration; connecting with students; and rethinking Physical Education lessons. In conclusion, teachers' experiences involved transformative responses to the limits faced in remote learning, including listening to students' voices and forming a study group for collaborative learning.

Keywords: Education, primary and secondary. Learning. Pandemics. COVID-19

Resumen: La implementación de la enseñanza remota como resultado de la pandemia COVID-19 se ha convertido en una realidad nueva y compleja para las comunidades escolares. En este contexto, el objetivo de este trabajo ha sido analizar las experiencias de profesores-investigadores de Educación Física con la enseñanza remota en Institutos Federales. Con base en la perspectiva freireana y en la teoría social del aprendizaje, la investigación se desarrolló con enfoque cualitativo y colaborativo, a través del método de la narrativa autobiográfica. Ocho profesores-investigadores participaron del estudio. Los datos se generaron a partir de narrativas elaboradas por los profesores-investigadores y se analizaron mediante comparaciones constantes. Como resultados, se identificaron cuatro temas: nuevos escenarios y desafíos; aproximación y colaboración entre pares; conectando con los estudiantes; y repensando las clases de Educación Física. En conclusión, las experiencias docentes implicaron respuestas transformadoras frente a los límites encontrados en la enseñanza remota, incluyendo escuchar a los estudiantes y formar un grupo de estudios y aprendizaje colaborativo.

Palabras clave: Educación primaria y Secundaria. Aprendizaje. Pandemias. COVID-19 


\section{LICENÇA DE USO}

Este é um artigo publicado em acesso aberto (Open Access) sob a licença Creative Commons Atribuição 4.0 Internacional (CC BY 4.0), que permite uso, distribuição e reprodução em qualquer meio, desde que o trabalho original seja corretamente citado. Mais informações em: https://creativecommons.org/licenses/by/4.0

\section{CONFLITO DE INTERESSES}

Os autores declararam que não existe nenhum conflito de interesses neste trabalho.

\section{CONTRIBUIÇÕES AUTORAIS}

Heidi Jancer Ferreira: Conceptualização, administração do projeto, participação no processo colaborativo de produção e análise de dados, redação preliminar e revisão do artigo - com destaque para o referencial teórico, metodologia, resultados e discussão.

Keila Miotto: Conceptualização, participação no processo colaborativo de produção e análise de dados, redação preliminar e revisão do artigo - com destaque para a introdução e metodologia.

Juscélia Cristina Pereira: Conceptualização, participação no processo colaborativo de produção e análise de dados, e redação preliminar do artigo - com destaque para a introdução, apresentação dos resultados e discussão.

Josué Lopes: Conceptualização, participação no processo colaborativo de produção e análise de dados, e redação preliminar do artigo - com destaque para a apresentação dos resultados e discussão.

Karla Queiroz Gontijo: Conceptualização e participação no processo colaborativo de produção e análise de dados.

Claudia Catarino Pereira: Participação no processo colaborativo de produção de dados, redação preliminar e revisão do artigo - com destaque para o referencial teórico e discussão.

Renata Beatriz Klehm: Participação no processo colaborativo de produção e análise de dados, e edição do artigo.

Wagner Edson Farias dos Santos: Conceptualização e participação no processo colaborativo de produção e análise de dados.

\section{FINANCIAMENTO}

O presente trabalho foi realizado sem o apoio de fontes financiadoras.

\section{AGRADECIMENTOS}

Instituto Federal de Educação, Ciência e Tecnologia do Sul de Minas Gerais IFSULDEMINAS. Instituto Federal de Educação, Ciência e Tecnologia do Triângulo Mineiro - IFTM.

\section{ÉTICA DE PESQUISA}

O projeto de pesquisa seguiu as Resoluções 466/12 e 510/2016 do Conselho Nacional de Saúde do Brasil. 


\section{COMO REFERENCIAR}

FERREIRA, Heidi Jancer; MIOTTO, Keila; PEREIRA, Juscélia Cristina; LOPES, Josué; GONTIJO, Karla Queiroz; PEREIRA, Claudia Catarino; KLEHM, Renata Beatriz; SANTOS, Wagner Edson Farias. E a educação física? Narrativas de professores-pesquisadores sobre as aulas remotas em institutos federais.

Movimento (Porto Alegre), v.27, p.e27070, jan./dez. 2021. Disponível em: https:// seer.ufrgs.br/Movimento/article/view/117478. Acesso em: [dia] [mês abreviado]. [ano]. DOI: https://doi.org/10.22456/1982-8918.117478

\section{RESPONSABILIDADE EDITORIAL}

Alex Branco Fraga*, Elisandro Schultz Wittizorecki*, Ivone Job*, Mauro Myskiw*, Raquel da Silveira*

*Universidade Federal do Rio Grande do Sul, Escola de Educação Física, Fisioterapia e Dança, Porto Alegre, RS, Brasil. 